\title{
Practice-based learning: Observations on One-Stop Centers in refugee settings
}

Chi-Chi Undie

Population Council

Josephine Ngebeh

Jane Harriet Namwebya

Joanina Karugaba

Follow this and additional works at: https://knowledgecommons.popcouncil.org/departments_sbsr-rh

Part of the Demography, Population, and Ecology Commons, Family, Life Course, and Society Commons, International Public Health Commons, Medicine and Health Commons, and the Migration Studies Commons How does access to this work benefit you? Let us know!

\section{Recommended Citation}

Undie, Chi-Chi, Josephine Ngebeh, Jane Harriet Namwebya, and Joanina Karugaba. 2019. "Practice-based learning: Observations on One-Stop Centers in refugee settings," Sauti/VOICE Program Brief no. 5. Nairobi: UNHCR EHAGL Africa Bureau and Population Council. 


\section{Practice-based Learning: Observations on One-Stop Centers in Refugee Settings}

\section{Background}

'One-Stop Centers' (OSCs) have grown in popularity for responding to sexual and gender-based violence (SGBV) in the East, Horn, and Great Lakes regions of Africa. OSCs attempt to provide an integrated, multi-sectoral response to SGBV survivors' needs in one physical location. A sole location for a multisectoral response eases survivors' access to critical services during a traumatic time, and can help mitigate survivors' trauma by ensuring survivors are attended to by fewer providers and do not have to repeatedly narrate their traumatic experience to different professionals. Where it is not feasible to provide services from all critical sectors under one roof or in one main location, a referral system connects survivors to any services not available at the primary location.

In resource-constrained settings, the most common services offered at OSCs include health care, psycho--social support, police and judicial services, as well as social support. Studies in non-refugee settings in the region have highlighted several OSC configurations: health facility-based OSCs and 'standalone' OSCs.

Health facility-based OSCs are either owned by the health facility, with services provided by health facility staff, or they are owned and run

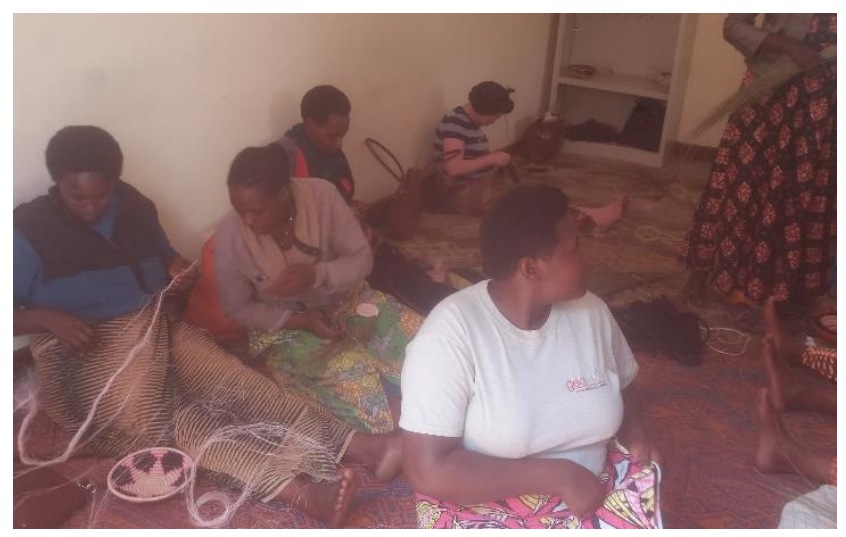
by non-governmental organizations (NGOs). Standalone OSCs tend to be NGO-owned and independently located, mainly providing legal and psycho-social support on site, with external referrals for health care. Studies in the region demonstrate that health facility-based OSCs that are owned and run by health facility staff are more effective in achieving the broadest range of desired health and legal outcomes for SGBV survivors.

In collaboration with the Population Council-led Africa Regional SGBV Network, the UNHCR East and Horn of Africa and Great Lakes (EHAGL) Africa Bureau has facilitated several new SGBV responses within its country operations. These interventions are bound to generate increased use of OSCs by SGBV survivors in refugee settings, necessitating an understanding of OSCs in these contexts. This program brief documents learnings and observations around OSCs in refugee settings from project visits to various operations under the UNCHR EHAGL Africa Bureau's mandate. 


\section{Learnings/Observations}

\section{Health facility-based OSCs are the norm}

The vast majority of OSCs in refugee settings participating in the Sauti/VOICE project are health facilitybased and are either supervised and staffed by government health providers or overseen by NGOs, but staffed by government health providers. Standalone OSCs are against the norm, but they do exist. In the urban refugee setting of Juba, South Sudan, for example, no health facilities have an OSC on their premises, but referrals are made to Juba Teaching Hospital's OSC. In addition, an NGO, Humanitarian Development Consortium (HDC), serves as a UNHCR implementing partner, providing non-medical OSC services to survivors referred from health facilities after medical care.

\section{Services offered by OSCs}

Because most OSCs tend to be situated within health facilities, they typically have a focus on medical services (e.g. HIV testing and postexposure prophylaxis, treatment for other STIs, emergency contraception, treatment of injuries) coupled with psychosocial support. Health facility-based OSCs generally provide legal support through referrals (rather than on site), except when the health facility is at a high level (e.g. an actual hospital, such as Kanyama Hospital in Lusaka, Zambia, whose

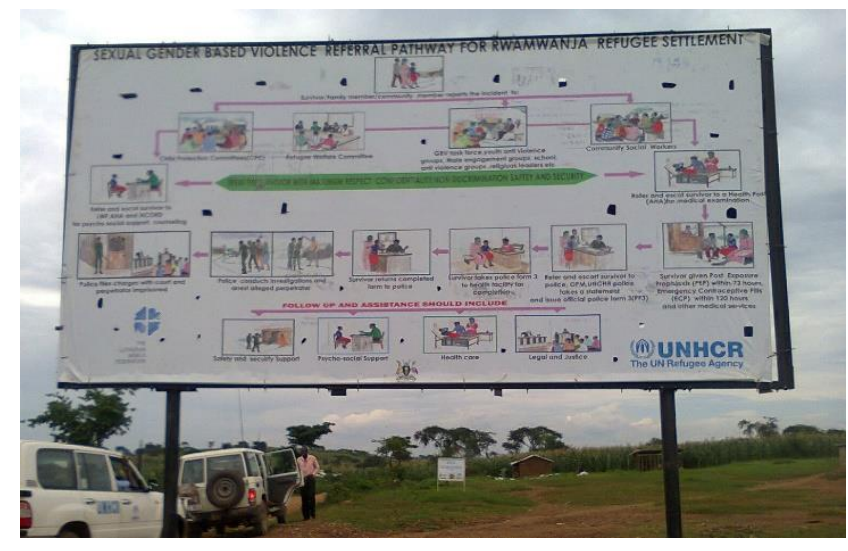
OSC has a police post on site). OSCs not affiliated with health facilities tend to prioritize on-site legal services in addition to psychosocial support.

\section{OSCs and age considerations}

In some refugee settings (e.g., some refugee camps in Rwanda), differing needs of child survivors and adult survivors are taken into account, with two separate OSCs co-existing-one devoted to child survivors, the other dedicated to adult counterparts. In such cases, implementing partners with the required expertise for attending to the population concerned work in collaboration with UNHCR to respond to survivors. In Mahama Refugee Camp, Rwanda, Save the Children International runs an OSC that responds specifically to child survivors under age 18, while the American Refugee Committee responds to survivors ages 18 and older.

\section{Not all health facilities have OSCs on-site}

As is in any setting-but particularly in low-resource settings-not all health facilities have OSCs on site. Health facilities without OSCs on site establish referral links to existing OSCs. Such referrals can pose a challenge where the initiating facility is not within close walking distance. Even when OSCs are located within health facilities, it is unusual for survivors to have 100 percent referral completion rates. These realities need to be taken into account when SGBV interventions are introduced to increase the uptake of comprehensive SGBV provided by OSCs.

\section{The existence of 'Para-OSCs' within health facilities}

Some health facilities have certain locations dedicated specifically to the Clinical Management of Rape (CMR). These may be viewed as 'para-OSCs,' as they are designed to facilitate rape survivors' access to all clinical services they may require. Para-OSCs are found in Maban, South Sudan, where a specific building in each health facility is devoted to CMR. Following clinical services, survivors are then referred to actual OSCs for other, non-clinical services.

In the absence of para-OSCs, survivors still obtain the clinical services they require, but usually have to do so by visiting several service delivery points within the health facility. 


\section{OSCs and transportation alternatives}

Transportation to OSCs for comprehensive care is a well-known barrier for survivors. UNHCR's operation in Juba, South Sudan, has addressed this challenge by making ambulances available to transport survivors from health facilities to OSCs. Where cost is not a barrier, this form of support for survivors is extremely valuable. However, with the new SGBV interventions introduced by the UNHCR EHAGL Africa Bureau into Juba, SGBV survivor identification is expected to increase, as is survivors' use of OSCs, making it important to consider the implications for the use of ambulances. Ambulances were incorporated into the response process to ensure rape survivors obtain time-sensitive health care. However, some new interventions (e.g. routine screening for SGBV), are geared toward identifying forms of SGBV beyond rape alone. Such an intervention is bound increase the number of survivors in need of transportation for situations that may be regarded as 'less urgent' (e.g. experience of emotional violence, as opposed to experience of rape). These are issues that should be discussed and addressed as country operations prepare to introduction survivor identification interventions, for example. 


\section{References}

Ajema C, Mukoma W, Mugyenyi C, Meme M, Kotut R, and Mulwa R. 2012. Improving the collection, documentation and utilisation of medico-legal evidence in Kenya; LVCT Kenya.

www.law.berkeley.edu/wp-content/uploads/2015/10/Kenya_Chain-of-Med-Legal-Evidence-

Rept LVCT 2012.pdf.

Keesbury J and Askew I, 2010. Comprehensive responses to gender based violence in low-resource settings: Lessons learned from implementation. Population Council. Lusaka, Zambia. https://pdfs.semanticscholar.org/9f6f/b3801fb2307bbdbfdce0d38f5d94992f5d3c.pdf.

Keesbury J, Onyango-Ouma W, Undie C, Maternowska C, Mugisha F, Kageha E, Askew I. 2012. A review and evaluation of multi-sectoral response services (one-stop centers) for gender-based violence in Kenya and Zambia. Population Council: Nairobi, Kenya. www.endvawnow.org/uploads/browser/files/popcouncil one stops.pdf.

Undie C, Birungi H, Namwebya J, Taye W, Maate L, Mak'anyengo M, Katahoire A, Kazungu DA, Kusasira D, Mirghani Z, Karugaba J. 2016. Screening for sexual and gender-based violence in emergency settings in Uganda: An assessment of feasibility. Nairobi, Kenya: Population Council. www.popcouncil.org/uploads/pdfs/2016RH ScreeningSGBV-Uganda.pdf.

Since 2006, the Population Council-led Africa Regional SGBV Network has worked to build effective responses to SGBV in low-resource settings, focusing on those who have experienced violence, as well as on violence prevention. From 2018-2020, the network is collaborating with the UNHCR EHAGL Africa Bureau in Nairobi, Kenya, to address the needs of survivors in refugee settings in the East, Horn, and Great Lakes Regions of Africa through the ViOlence Response and Prevention through Information, Communication, and Education (VOICE) project. 'Voice' is translated as 'Sauti' in Kiswahili, and represents the project's emphasis on amplifying the voices of SGBV survivors and the efforts of those that work with them (UNHCR implementing partners and the network's civil society organizations), in order to broaden the reach of effective SGBV responses across the region.

(C)2019 UNHCR EHAGL Africa Bureau and the Population Council, Inc.

Citation: Chi-Chi Undie, Josephine Ngebeh, Jane Harriet Namwebya, Joanina Karugaba. 2019. 'Practicebased learning: Observations regarding One-Stop Centers in refugee settings.' The Sauti/VOICE Program Brief Series, Brief 5. Nairobi, Kenya: UNHCR EHAGL Africa Bureau and Population Council.

\author{
UNHCR EHAGL Africa Bureau \\ Contact: \\ Josephine Ngebeh \\ UNHCR Regional Service Centre \\ APHRC Campus, Kitisuru \\ P. 0. Box 43801-00100 \\ Nairobi, Kenya \\ ngebeh@unhcr.org
}

\author{
UNHCR Geneva Contact: \\ Joanina Karugaba \\ UNHCR Geneva \\ Case Postale 2500 \\ 1211 Genève 2 Depôt \\ Switzerland \\ karugaba@unhcr.org
}

\author{
Africa Regional SGBV Network Contact: \\ Chi-Chi Undie \\ Population Council \\ Avenue 5, Rose Avenue \\ Hurlingham \\ P. O. Box $17643-00500$ \\ Nairobi, Kenya \\ cundie@popcouncil.org
}

